\title{
Polymer PSQ-L Notch Filter Fabricated by Simple Nanoimprint Process
}

\author{
Jie Teng ${ }^{\mathrm{a}, \mathrm{b}, \mathrm{d}}$, Xiuyou Han ${ }^{\mathrm{a}, \mathrm{b}}$, Hongbo Zhang ${ }^{\mathrm{b}, \mathrm{c}}$, Jinyan Wang ${ }^{\mathrm{b}, \mathrm{c}}$, Xigao Jian ${ }^{\mathrm{b}, \mathrm{c}}$, Stijn Scheerlinck ${ }^{\mathrm{d}}$, \\ Geert Morthier $^{\mathrm{d}}$, Roel Baets ${ }^{\mathrm{d}}$, Mingshan Zhao* a, b \\ ${ }^{a}$ School of Physics and Optoelectronic Technology, Dalian University of Technology, Dalian, \\ 116023, China \\ ${ }^{\mathrm{b}}$ Photonics Research Center, Dalian University of Technology, Dalian, 116023, China \\ ${ }^{\mathrm{c}}$ Department of Polymer Science\& Materials, Dalian University of Technology, 116012, Dalian, \\ China \\ d Photonics Research Group, INTEC-department, Ghent University-IMEC, Ghent, B-9000, Belgium
}

\begin{abstract}
Polymers are emerging as an important material in the field of integrated optics. In this paper, we propose a simple method to fabricate polymer waveguides by using a novel polymer PSQ-L. The high index polymer PSQ-LH is used as a core material and the low index polymer PSQ-LL is used as a cladding material. The waveguide circuits are replicated by using a UV-based soft lithography process. Unlike in conventional imprint processes, the imprint step for structuring is done first on the cladding layer rather than on the core layer and is followed by a spin-coating step to fill the imprinted features with core layer material. The all-polymer microring resonators are fabricated by this method. The coupling efficiency between the straight waveguides and the ring is adjusted by controlling the gap distance between the straight waveguides and the ring. About $20 \mathrm{~dB}$ extinction ratio and a high $\mathrm{Q}$ factor of $3.4 \times 10^{4}$ is obtained for critically coupled PSQ-L ring resonator.
\end{abstract}

Keywords: polymer waveguide, nanoimprint, microring resonator, notch filter

\section{INTRODUCTION}

Polymers are emerging as an alternative material to silica in the field of integrated optics[1]. The prominent advantage of using polymer to fabricate waveguides is that the cost of the whole circuit can be highly reduced by simple film preparation and simple fabrication process. Apart from conventional lithography and etching fabrication process as semiconductor material, a lot of fabrication methods based on nanoimprint lithography technology and soft-lithography for polymer waveguides have been extensively studied in the past few years [2, 3].

In this paper, we propose a simple method to fabricate polymer waveguides by using a novel polymer PSQ-L[4]. The high index polymer PSQ-LH is used as a core material and the low index polymer PSQ-LL is used as a cladding material. The waveguide circuits are replicated by a UV-based soft lithography process. Unlike in conventional imprint processes, the imprint step for structuring is done first on the cladding layer rather than on the core layer and is followed by a spin-coating step to fill the imprinted features with core layer material. This waveguide cross-section design smartly avoids controlling the thickness of the residual core layer. We use this approach to fabricate notch filters based on simple microring resonators. The critical coupling condition of the ring resonators is achieved when with a gap of $1 \mu \mathrm{m}$ and a coupling length of $50 \mu \mathrm{m}$ for $400 \mu \mathrm{m}$-radius ring resonator. About $20 \mathrm{~dB}$ extinction ratio and a high Q factor of $3.4 \times 10^{4}$ is obtained for critically coupled PSQ-L ring resonator.

\section{EXPERIMENTAL DETAILS}

\subsection{Materials}

* Corresponding author. Email:mszhao@dlut.edu.cn

5th International Symposium on Advanced Optical Manufacturing and Testing Technologies: Optoelectronic Materials and Devices for Detector, Imager, Display, and Energy Conversion Technology, edited by Yadong Jiang, Bernard Kippelen, Junsheng Yu, Proc. of SPIE Vol. 7658, 76580F - @ 2010 SPIE · CCC code: 0277-786X/10/\$18 · doi: 10.1117/12.867977 
The polymer PSQ-L is a kind of silicate-based inorganic-organic hybrid polymer [4]. It is purely liquid (solvent free), UV curable and compatible with soft-lithography.

The Polymer PSQ-L exists in two forms: a high index polymer PSQ-LH and a low index polymer PSQ-LL. The high index polymer PSQ-LH is used as a core material and the low index polymer PSQ-LL is used as a cladding material. This polymer film shows good optical properties (Table 1$)$ and high thermal stability $\left(1 \% \mathrm{Td}\right.$ is above $300{ }^{\circ} \mathrm{C}$ in air and $340{ }^{\circ} \mathrm{C}$ in nitrogen), which makes it a good candidate for polymer waveguides applications. The optical loss of the film is less than $0.3 \mathrm{~dB} / \mathrm{cm}$ at $1310 \mathrm{~nm}$ and less than $0.9 \mathrm{~dB} / \mathrm{cm}$ at $1550 \mathrm{~nm}$.

The optical properties of PSQ-L films are characterized by prism coupling (SPA-4000). The optical loss of the film (slab waveguide) is measured by immersion oil technology [5] and it is a good approximation for the absorption loss of the material itself.

TABLE 1. Properties of polymer PSQ-L

\begin{tabular}{lll}
\hline & PSQ LL & PSQ LH \\
\hline Refractive Index @1310nm & 1.456 & 1.517 \\
Refractive Index @1550nm & 1.454 & 1.515 \\
Birefringence $\left(\mathrm{n}_{\mathrm{TE}}-\mathrm{n}_{\mathrm{TM}}\right)$ & $<0.0005$ & $<0.0005$ \\
Thermo-optic coefficient $\left(/{ }^{\circ} \mathrm{C}\right)$ & $-2.2 \times 10^{-4}$ & $-2.4 \times 10^{-4}$ \\
Propagation Loss & not measured & $<0.9 \mathrm{~dB} / \mathrm{cm} @ 1550 \mathrm{~nm}$ \\
(slab waveguide) & not measured & $<0.3 \mathrm{~dB} / \mathrm{cm} @ 1310 \mathrm{~nm}$ \\
Glass Transition Temp. (Tg) & not detectable & not detectable \\
Degradation Temp. $(1 \mathrm{wt} \%)$ & $322 \pm 10^{\circ} \mathrm{C}$ (in air) & $303 \pm 10^{\circ} \mathrm{C}$ (in air) \\
& $370 \pm 10^{\circ} \mathrm{C}\left(\right.$ in $\left.\mathrm{N}_{2}\right)$ & $343 \pm 10^{\circ} \mathrm{C}\left(\right.$ in $\left.\mathrm{N}_{2}\right)$ \\
Film Surface Roughness $(\mathrm{AFM})$ & $<0.5 \mathrm{~nm}$ & $<0.5 \mathrm{~nm}$ \\
\hline
\end{tabular}

\subsection{Fabrication Process}

The waveguide circuits are replicated by a UV-based soft lithography process (Fig.1). The PDMS mold is made from a SU-8 master mold by cast-molding process[2]. First, a drop of pure PSQ-LL is deposited on the silicon wafer, and then the PDMS mold is put on top. After 20 minutes imprint time, it is exposed to the UV lamp for 3 minutes. After that, the PDMS mold is peeled off and the polymer is baked for $1 \mathrm{~h}$ at $180^{\circ} \mathrm{C}$ to allow for solidification after UV exposure. To improve the adhesion to the second layer, 5 minutes of oxygen plasma etching is done on the first layer. Then the core layer PSQ-LH is spin-coated on the first layer with high speed (9500rpm). Finally, the sample is post baked at $180^{\circ} \mathrm{C}$ for $2 \mathrm{~h}$ and $200^{\circ} \mathrm{C}$ for another $2 \mathrm{~h}$ to allow for full polymerization.

To fulfill the single mode condition of the waveguide for the ring resonator, the waveguide is designed with a width of $3 \mu \mathrm{m}$ and a height of $2 \mu \mathrm{m}(\mathrm{w}=3 \mu \mathrm{m}, \mathrm{h}=2 \mu \mathrm{m}$ in Fig.2(d)). The thickness of the residual layer (h1 in Fig.2(d)) is controlled by the spin-coating speed of the core layer. In order to avoid extra bending loss caused by thick residual layer, the spincoating speed of the core layer is set as high as $9500 \mathrm{rpm}$. This waveguide cross-section design smartly avoids accurate controlling the thickness of the residual core layer.

A SEM (Scanning electron microscope) picture of the cross section of the waveguide is shown in Fig.2(a),(b). The small roughness on the sidewalls originates from the SU-8 mold. A cross section SEM picture of the waveguide after spincoating the second layer is shown in Fig.2(c). 
1

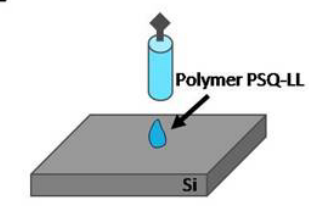

Deposit a drop of polymer PSQ-L

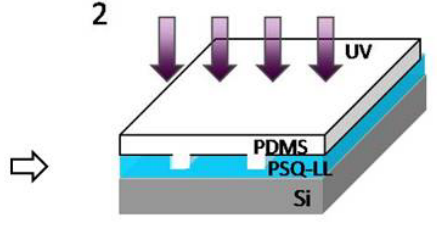

Imprint, UV exposure

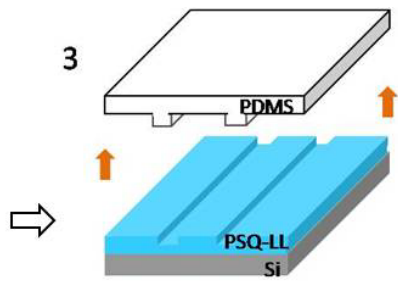

Peel off the PDMS mold
4

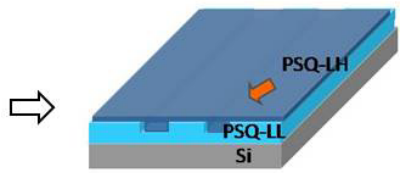

Spin-coating PSQ-LH

Fig.1: UV-based soft-lithography process for fabrication of PSQ-L waveguides

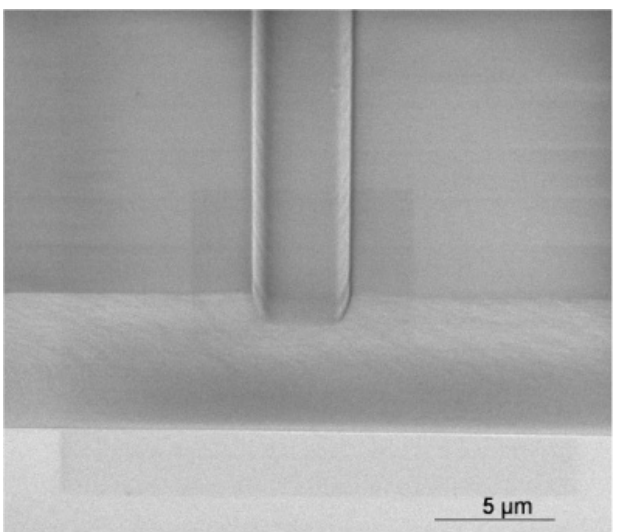

(a)

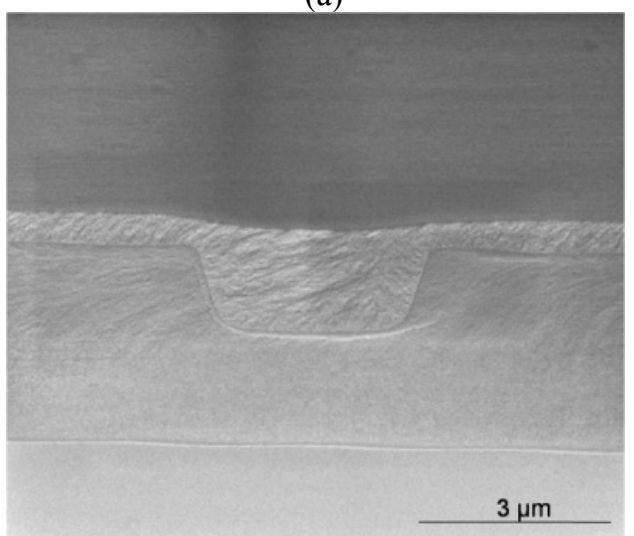

(c)

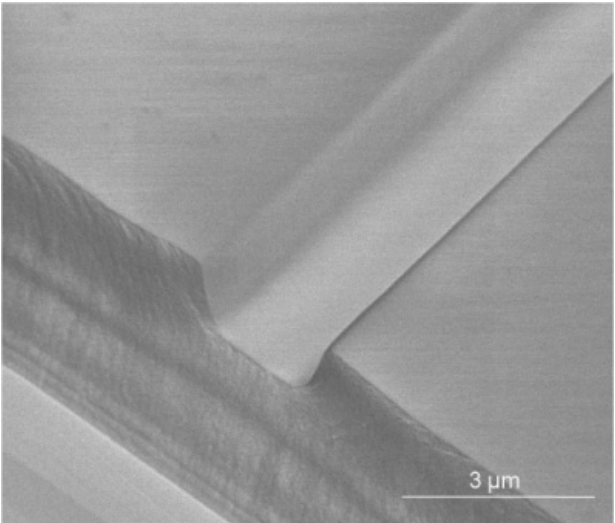

(b)

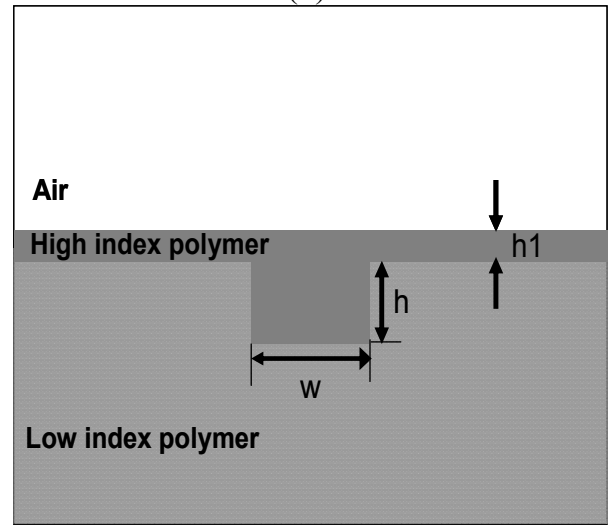

(d)

Fig.2: (a) (b) SEM picture of the imprinted low index PSQ-LL layer (c) SEM picture of waveguide cross-section (after spin-coating the high index PSQ-LH layer)

(d) The cross-section structure of the waveguide

\section{RESULTS AND DISCUSSION}

The transmission spectrum of the device is measured by coupling light from a tunable laser to the waveguide via a single mode fiber. The transmitted light is also collected by a single mode fiber to the power meter. A polarization controller is used at the input port to select the polarization. The coupling efficiency between the straight waveguides and the ring is adjusted by controlling the gap distance between the straight waveguides and the ring. The critical coupling condition[6] is achieved when with a gap of $1 \mu \mathrm{m}$ and a coupling length of $50 \mu \mathrm{m}$ for $400 \mu \mathrm{m}$-radius ring resonator. Fig. 3 shows the measured TE mode transmission spectrum of the notch filter at critical coupling condition. About $20 \mathrm{~dB}$ extinction ratio for critically coupled PSQ-L ring resonator is obtained.

The resonators has a free spectral range (FSR) of $0.6 \mathrm{~nm}$, a 3-dB bandwidth of $0.045 \mathrm{~nm}$, corresponds to a $\mathrm{Q}$ factor of $3.4 \times 10^{4}$. The transmission spectrum of notch filters is fit by Lorentz function. The round trip attenuation factor A and the 
transmission factor $\mathrm{T}$ are extracted: for $\mathrm{TE}$ mode, $\mathrm{T}=85 \%, \mathrm{~A}=0.81$, corresponds to a scattering loss $1.6 \mathrm{~dB} / \mathrm{cm}$ for bent waveguides[7].

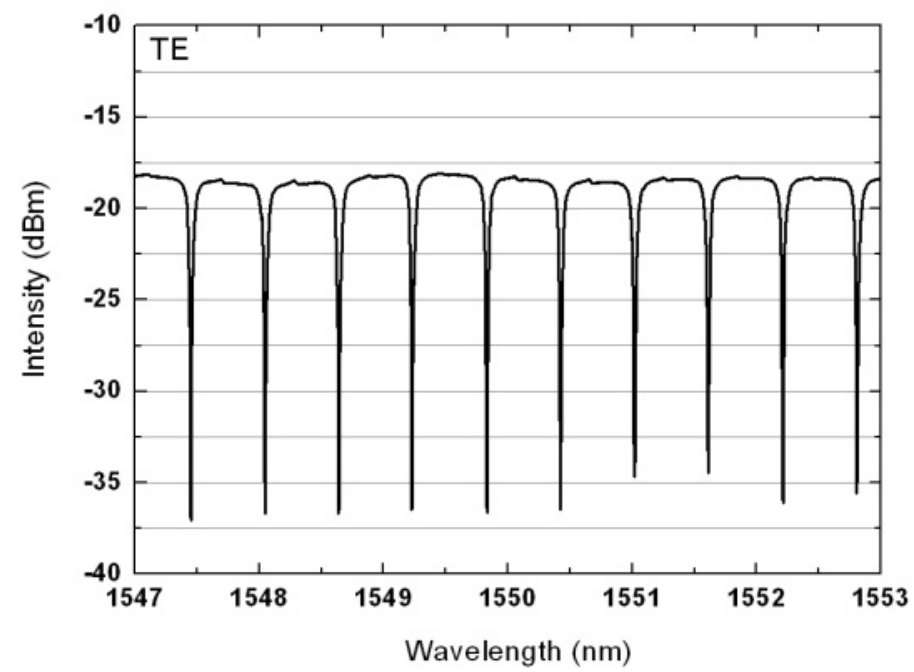

Fig.3: Transmission spectrum of notch filter at critical coupling condition (Dimension parameters of the notch filter: $\mathrm{R}=400 \mu \mathrm{m}$, Gap $=1 \mu \mathrm{m}, \mathrm{L}=50 \mu \mathrm{m}$ )

\section{CONCLUSIONS}

We propose a simple UV-based soft-lithography process for fabrication of polymer PSQ-L waveguides. The polymer PSQ-L ring resonators are fabricated and characterized. The critical coupling condition of the ring resonator is achieved by adjusting the gap distance between the straight waveguides and the ring. About $20 \mathrm{~dB}$ extinction ratio and a high $\mathrm{Q}$ factor of $3.4 \times 10^{4}$ is obtained.

\section{ACKNOWLEDGEMENTS}

This work was supported in part by Chinese National Science Foundation under Grant No. 60577014, No. 60807015, Specialized Research Fund for the Doctoral Program of Higher Education (No. 200801411037). Jie Teng acknowledges CSC scholarship and Gent University BOF co-funding for financial support.

\section{REFERENCES}

1. H. Ma, A. K. Y. Jen, and L. R. Dalton, Adv. Mater. 14, 1339 (2002).

2. J. K. S. Poon, Y. Y. Huang, G. T. Paloczi, and A. Yariv, IEEE Photon. Technol. Lett. 16, 2496 (2004).

3. C. Y. Chao and L. J. Guo, J. Vac. Sci. \& Technol. B 20, 2862 (2002).

4. H. B. Zhang, J. Y. Wang, L. K. Li, Y. Song, M. S. Zhao, and X. G. Jian, Journal of Macromolecular Science, Part A: Pure and Applied Chemistry 45, 232 (2008).

5. C. C. Teng, Appl. Opt. 32, 1051 (1993).

6. A. Yariv., Electronics Letters, 36(4), 321, (2000).

7. J. Teng, S. Stijn, H. B. Zhang, X. G. Jian, M. Morthier, R. Beats, X. Y. Han, and M. S. Zhao, IEEE Photon. Technol. Lett. ,to be published, (2009) 